\title{
NGF IMPROVES NEURITE FASCICULATION OF EMBRYONIC RAT CEREBRAL CORTICAL NEURAL STEM CELLS ON EVAL SUBSTRATES UNDER SERUM FREE CONDITIONS
}

\author{
Chin-Huang Hung, Tai-Horng Young \\ Institute of Biomedical Engineering, College of Medicine and Engineering, \\ National Taiwan University, Taipei, Taiwan
}

\begin{abstract}
The behaviors of multipotential neural stem cells are regulated by several factors, including culture substrates, soluble factors, and cell-cell interactions. The purpose of this study was to explore the effects of cell-cell and cell-substrate interactions on developmental potential of neural stem cells from embryonic rat cerebral cortex at neurosphere level in the presence of nerve growth factors $(N G F)$. The results suggested that, in combination with NGF, EVAL substrates could induce neurite fasciculation of differentiated forming-neurosphere cells under serum free conditions. Quantitative analysis of process growth reveals that, under serum free conditions, when NGF was present the process breadth was significantly larger than that of neurospheres cultured without NGF. In contrast, when serum were added in the medium, regardless of the addition of NGF or not, the neurospheres were induced into typically an extensive cellular substratum of protoplasmic cells upon which process-bearing cells spread. It indicated that, when serum was present, the differentiated GFAPpositive astrocytes layer could serve as a supported architectural for growth and survival of processbearing cells. At this time, neurites were failed to fasciculate. Here, we proposed that the mediation of cell-biomaterial interaction by cell-cell interaction should be taken into account for regulation of neurites fasciculation. Moreover, the pattern of neural stem cell growth on EVAL subtrates with or without NGF in the absence or presence of serum in this studies suggested that neurons are more adherent to glail cells than to other neurons but are more adherent to other neurons than to EVAL substrates.
\end{abstract}

Biomed Eng Appl Basis Comm, 2006(August); 18: 207-213.

Keywords: poly (ethylene-co vinyl alcohol) (EVAL); nerve growth factor (NGF); neural stem cells

\section{INTRODUCTION}

Received: March 15, 2006; Accepted: June 14, 2006

Correspondence: Tai-Horng Young, Professor

Institute of Biomedical Engineering, College of Medicine and Engineerimg, National Taiwan University, Taipei 100, Taiwan

E-mail: thyoung@ha.mc.ntu.edu.tw
The discovery of neural stem cells in the central nervous system (CNS) and their capacity to regenerate functional neural cells have raised hopes for once untreatable diseases and injuries to the brain and spinal cord. In vitro culture system, the plasticity of neural stem cells was thought to be controlled and manipulated by the effects of extrinsic and intrinsic signals coming from substrates, medium components, and several complex interactions among cells [1-2]. These multipotential neural stem cells can divide and expand to form free-floating neurospheres when grown 
in defined medium supplemented with basic fibroblast growth factor (bFGF), epidermal growth factor (EGF), or transforming growth factor $\alpha$ (TGF- $\alpha)$ [1,3-4]. In addition, ciliary neurotrophic factor (CNTF) and insulin-like growth factor-1 (IGF-1) have also been reported to function as key cues in regulation of development of neural stem cells [5-6]. Besides the diffusible factors, signal coming from cell-cell contact also has an effect on the transition of multipotential neural stem cells to postmitotic cells of different types $[2,7]$. However, when exposed to suitable substrates in the absence of these mitogens, these cells attach and differentiate into neurons, astrocytes, and oligodendrocytes. However, numerous natural and synthetic polymers have been used as substrates or scaffolds for peripheral and central nerve regeneration in vitro or in vivo [8]. It is reasonable to assume that biomaterials may stimulate or inhibit the proliferation and differentiation of neural stem cells.

According to our previous studies, EVAL and PVA substrates would exert different influences on the behavior of neural stem cells under serum free conditions [9]. It is possible that neural stem cells respond to different substrates, and their fate determination depends on the chemical properties of the substrates. In this study, the effect of nerve growth factors (NGF) on growth and differentiation of embryonic rat cerebral cortical stem cells on EVAL substrates under the same conditions was explored. NGF plays an important role in the developments and survival of certain neurons in the CNS and could improve better neurites growth. In addition, it has also been suggested that the regulation of neurite fasciculation was determined by the affinitive competition between neuron-neuron and neuronsubstrates $[10]$. Thus, this study proposed that, in combination with nerve growth factors, EVAL substrates could induce neurite fasciculation of differentiated cortical neural stem cells under serum free conditions. The information should be useful for the development of biomaterials to regulate the morphology and differentiation of neural stem cells and their eventual manipulation to replace lost or dysfunctional neurons following trauma or disease.

\section{MATERIALS AND METHODS}

\subsection{Fabrication of EVAL Membranes}

EVAL (E105A, Kuraray, Japan, containing ca. 56 mole \% vinyl alcohol) membranes were prepared by using the dry process of the phase inversion method [11]. Circular membranes (1.5 cm in diameter) suitably sized for 24-well tissue culture polystyrene plates (Corning, New York, USA) were cut from the prepared membranes, and were placed in wells by placing a silicon rubber ring on top of each membrane. Subsequently, membranes were sterilized with $70 \%$ alcohol under ultraviolet light overnight and then rinsed extensively with phosphate-buffer saline (PBS) for culturing cortical neural stem cells.

\subsection{Isolation and Culture of Cortical Neural Stem Cells}

Cortical neural stem cells were prepared from pregnant Wistar rat embryos on day 14-15 according to a protocol detailed previously [1-2]. Briefly, rat embryonic cerebral cortices were dissected, cut into small pieces and mechanically triturated in cold Hank's balanced salt solution (HBSS) containing $5.4 \mathrm{mM} \mathrm{KCl}$, $0.3 \mathrm{mM} \mathrm{Na} \mathrm{HPO}_{4} \cdot 7 \mathrm{H}_{2} \mathrm{O}, 0.4 \mathrm{mM} \mathrm{KH} \mathrm{PO}_{4}, 4.2 \mathrm{mM}$

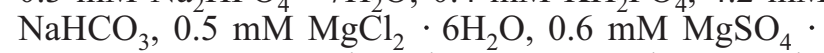
$7 \mathrm{H}_{2} \mathrm{O}, 137 \mathrm{mM} \mathrm{NaCl}$, and $5.6 \mathrm{mM}$ D-glucose. The dissociated cells were collected by centrifugation and were resuspended in a serum-free medium containing DMEM-F12, $8 \mathrm{mM}$ glucose, glutamine, $20 \mathrm{mM}$ sodium bicarbonate, $15 \mathrm{mM}$ HEPES and N2 supplement $(25 \mathrm{~g} / \mathrm{ml}$ insulin, $100 \mathrm{~g} / \mathrm{ml}$ human apotransferrin, $20 \mathrm{nM}$ progesterone, $30 \mathrm{nM}$ sodium selenite, $\mathrm{pH}$ 7.2) [12]. The number of live cells was counted by trypan blue exclusion assay in a hemocytometer.

Cerebral cortical neural stem cells were purified and cultured in T25 culture flasks (Corning, New York, USA) at a density of 50,000 cells $/ \mathrm{cm}^{2}$ in the above culture medium in the presence of bFGF at a concentration of $20 \mathrm{ng} / \mathrm{ml}$. Cultures were maintained at $37^{\circ} \mathrm{C}$ in a humidified atmosphere of $95 \%$ air $/ 5 \% \mathrm{CO}_{2}$. After 1 to 3 days in vitro, cells were undergoing cell division and the proliferating cells formed clusters of cells, termed neurospheres, which were suspended in the medium. Subsequently, adherent cells were discarded and suspended neurospheres were collected by centrifugation, mechanically dissociated and subcultured as single cells in a new T25 culture flask at a density of 50,000 cells $/ \mathrm{cm}^{2}$ in the fresh culture medium containing the same concentration of bFGF. These cells grew into new spheres in the subsequent 23 days, that is, single cells proliferated and formed new neurospheres. The procedure of subculture was repeated again to achieve the purified cortical neural stem cells and proliferating neurospheres. The plasticity of these purified cortical neural stem cells was then identified by the method of immunocytochemistry with anti-nestin, anti-NSE, and anti-GFAP. Subsequently, these purified neurospheres were seeded on EVAL substrates at 125 neurospheres $/ \mathrm{cm}^{2}$ in the presence or absence of NGF $(20 \mathrm{ng} / \mathrm{ml})$ under serum or serum-free conditions after bFGF withdrawal. At indicated time points, 
morphologies of cultured neurospheres were observed under a phase contrast microscope (Zeiss LAMBDA 10-2, Germany).

\subsection{Quantification of Process Length and Breadth}

Digital photomicrographs were taken of random fields of neurospheres at indicated experimental points. Quantification of process growth was evaluated by the end-to-end distance of extensive processes. The lengths of 10 longest processes (neurites from neurons or processes from glial cells) per neurosphere were estimated from the edge of the neurospheres to the tip of the processes in linear form. And the process breadth was measured from five random crossdistances of 5 fasciculated processes per neurosphere. Process lengths and breadths were measured by tracing the processes using NIH Image software (ImageJ). The length and breadth of processes of twelve independent neurospheres were calculated at each experiment, and the means and standard error of mean (SEM) were also calculated [13-14].

\subsection{Immunocytochemistry}

For immunocytochemical characterization, cultured cells were fixed in ice-cold $4 \%$ paraformaldehyde in PBS for $20 \mathrm{~min}$ and washed three times in PBS at indicated time points. After fixing, cells were incubated with primary antibodies diluted in PBS containing $0.3 \%$ Triton $\mathrm{X}-100$ and $10 \%$ bovine serum albumin for $2 \mathrm{~h}$ at $37^{\circ} \mathrm{C}$. The primary antibodies and their dilution used in this study were mouse antinestin monoclonal antibody (anti-nestin; 1:1000; Chemicon, Temecula, CA), rabbit anti-microtubuleassociated protein 2 polyclonal antibody (anti-MAP-2; 1:500; Chemicon, Temecula, CA), mouse anti- $\beta$ tubulin-III monoclonal antibody (anti- $\beta$-tubulin-III; 1:200; Chemicon, Temecula, CA), rabbit anti-glial fibrillary acidic protein polyclonal antibody (antiGFAP; 1:500; Chemicon, Temecula, CA) [15-18]. FITC- and Rhodamine-conjugated secondary antibodies were used to visualize the signal by reacting with cells for $30 \mathrm{~min}$ at room temperature. The secondary antibodies and their dilution were FITCconjugated goat anti-mouse IgG (preabsorbed with rabbit and rat serum protein; 1:100; Chemicon, Temecula, CA), FITC-conjugated donkey anti-rabbit IgG (preabsorbed with rabbit and rat serum protein; 1:100; Chemicon, Temecula, CA) and rhodamineconjugated goat anti-mouse IgG. (preabsorbed with rabbit and rat serum protein; 1:100; Chemicon, Temecula, CA). Immunostained cells were visualized by indirect fluorescence under the fluorescent microscope (Axiovert 100TV, Germany).

\section{RESULTS AND DISCUSSION}

The plasticity of proliferation and differentiation of neural stem cells was identified by the method of immunocytochemical stainings with anti-nestin, antiMAP-2, and anti-GFAP, which are immunoreactive for proliferating neural stem cells, differentiated neurons and astrocytes, respectively. Figure 1 shows that most of neurosphere-forming cells were immunoreactive for nestin, an intermediate filament protein specifically found in neuroepithelial stem cells [15], and demonstrates that these neurospheres remain the ability of proliferation. Next, to identify the differentiating ability of neural stem cells, neurospheres were seeded onto poly-D-lysine-coated $(50 \mathrm{ng} / \mathrm{ml})$ glass cover slips after bFGF withdrawal to allow cell attachment and differentiation. After $3 \mathrm{~d}$ of culture, neuropspheres had attached onto poly-D-lysine-coated glass cover slips and neurites extended and cells migrated out from neurospheres were observed; see Figure 2(a). Because these cultures might contain a heterogeneous population of cells at different stages of neuronal and glial development, antibodies to different marker proteins were used to determine their phenotypes immunocytochemically. MAP-2-(neurons), $\beta$ tubulin-III-, and GFAP- (astrocytes) immunoreactive cells were present; see Figure 2(b), (c), and (d). These results confirm previous studies suggested that cells isolated from embryonic rat cerebral cortex proliferate to produce clusters of cells with antigenic properties of neuroepithelial stem cells [1-2], and these neurosphereforming cells can be induced to differentiate into neurons and astrocytes under appropriate conditions.

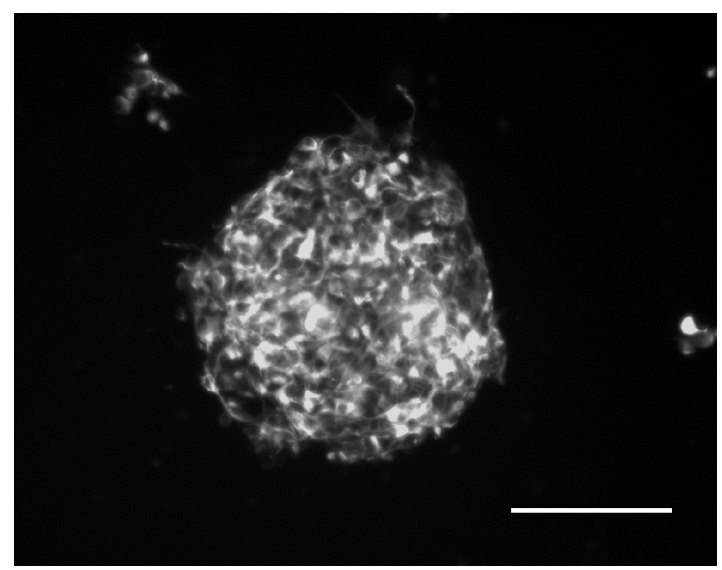

Fig. 1. The phase-contrast image of a neurosphere, generated from embryonic rat cerebral cortex, indicating cells were immunoreactive for nestin, an intermediate filament protein specifically found in neuroepithelial stem cells. Scale bar $=100 \mu \mathrm{m}$. 
(a)

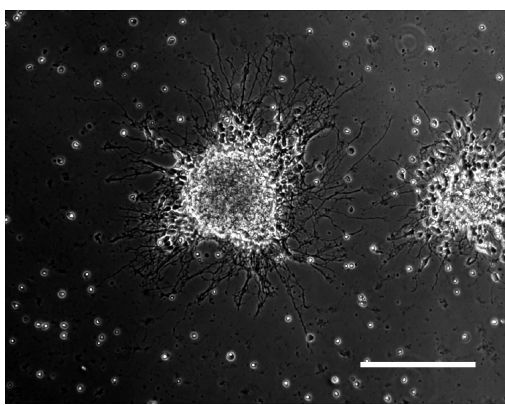

(b)
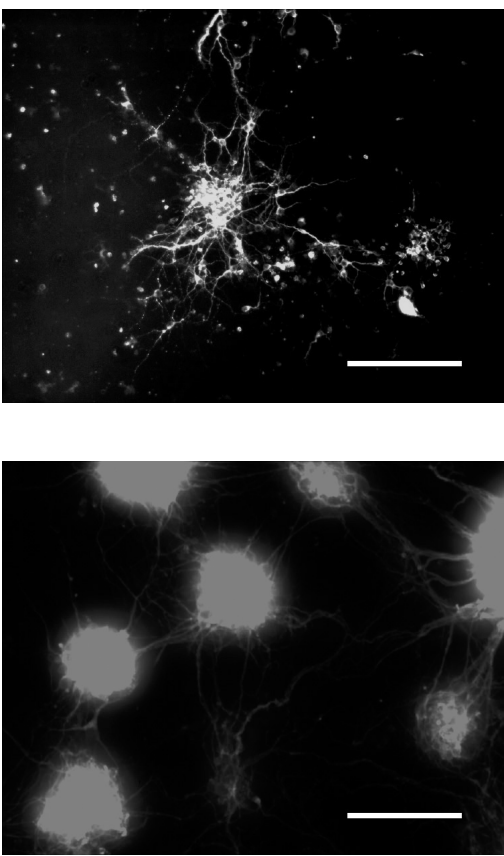

(c)

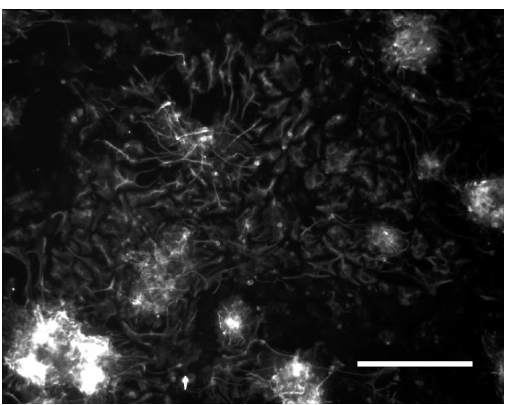

Fig.2. Neurospheres cultured on poly-D-lysinecoated glass cover slips. (a) Neurites extended and cells migrated out from neurospheres after $3 \mathrm{~d}$ of culture. (b) MAP-2- (neurons), (c) $\beta$-tubulin-III(neurons), and (d) GFAP- (astrocytes) immunoreactive cells were present after $3 \mathrm{~d}$ of culture. Scale bar $=\mathbf{2 0 0} \mu \mathrm{m}$.
After isolation and purification of the embryonic cortical neural stem cells, these bFGF-responsive neurospheres were then seeded onto EVAL substrates under serum-free conditions without the addition of NGF. As shown in Figure 3(a), after 3 d of culture, neurospheres had attached onto EVAL substrates and several straight and thin proecesses were extended out from the neurospheres. After all, when NGF were added to above culture conditions, as shown in Figure $3(b)$, processes were not only extended out from the neursopheres but also fasiculated to form neurofilament bundles after $3 \mathrm{~d}$ of culture in vitro. It is noticed that very few of these neurosphere-forming cells migrated out from their original aggregated under serum-free conditions, regardless of addition of NGF. Figure 4 shows the quantitative analysis of process growth by measuring process length and breadth on EVAL substrates in the presence or absence of NGF under serum or serum-free conditions. The process length and breadth on EVAL substrates without NGF

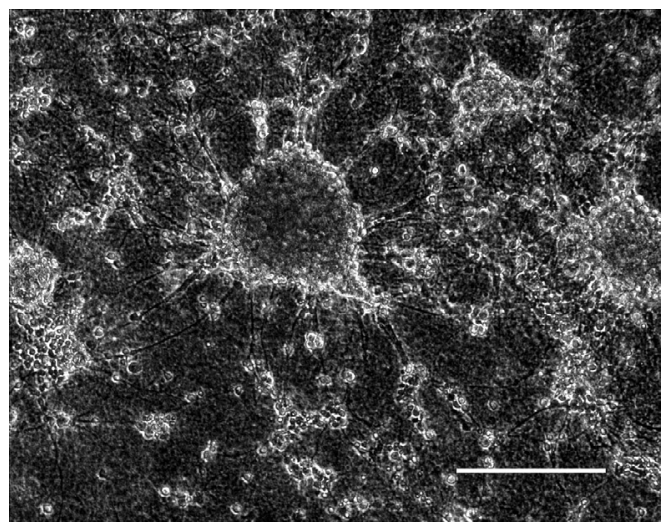

(a)

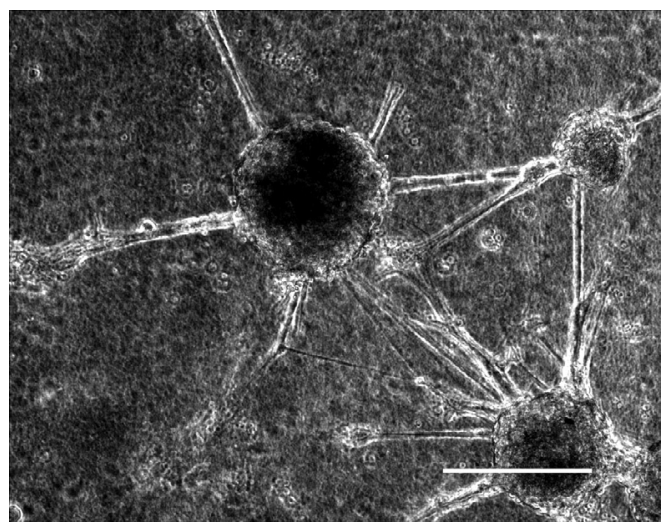

(b)

Fig. 3. Neurospheres cultured on EVAL substrates (a) with or (b) without the addition of NFG under serum-free conditions. Scale bar $=\mathbf{2 0 0} \mu \mathrm{m}$. 


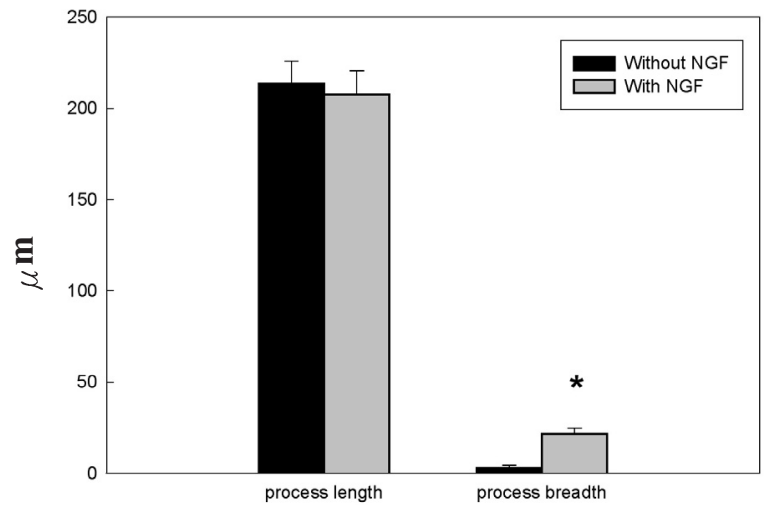

Fig. 4. Quantification of process growth of neurospheres on EVAL substrates under serum-free conditions at 125 neurospheres/ $\mathrm{cm}^{2}$ after $3 \mathrm{~d}$ of culture. Values represent means $\pm S E M$ of 10 independent neurospheres. Asterisk denotes significant differences $(p<0.05)$ as determined by Student 's t-test.

under serum-free conditions were $213.6 \pm 12.3 \mu \mathrm{m}$ and $3.1 \pm 1.2 \mu \mathrm{m}$, and were $207.6 \pm 13.1 \mu \mathrm{m}$ and 21.6 $\pm 3.2 \mu \mathrm{m}$ when NGF were added. Under serum-free conditions, the process length of differentiated neurospheres on EVAL substrates without the addition of NGF had no significant difference from that in the presence of NGF. However, under the same conditions, when NGF was added in the above culture system the process breadth was significantly larger than that of neurospheres cultured without NGF. It is noted that no obvious protoplasmic cells were observed in the serum-free medium.

Next experiment, we want to see whether NGF has the same effects on regulation of the process growth and differentiation of neurosphere-forming cells on EVAL substrates if the serum proteins were present in the culture system. As shown in Figure 5 (a), regardless of the addition of NGF or not, the neurospheres were induced into typically an extensive cellular substratum of protoplasmic cells upon which process-bearing cells spread. The protoplasmic cells, exhibiting large, flat cell bodies with very few processes, would migrate far away from the neurospheres and the process-bearing cells grown on these protoplasmic cell layers. These protoplasmic cell layers were characterized as GFAP-immunoreactive astrocytes; see Figure 5(b). Therefore, when serum was present, the differentiated GFAP-positive astrocytes layer could serve as a supported architectural for growth and survival of process-bearing cells. It is notice that a great number of cells migrated out far

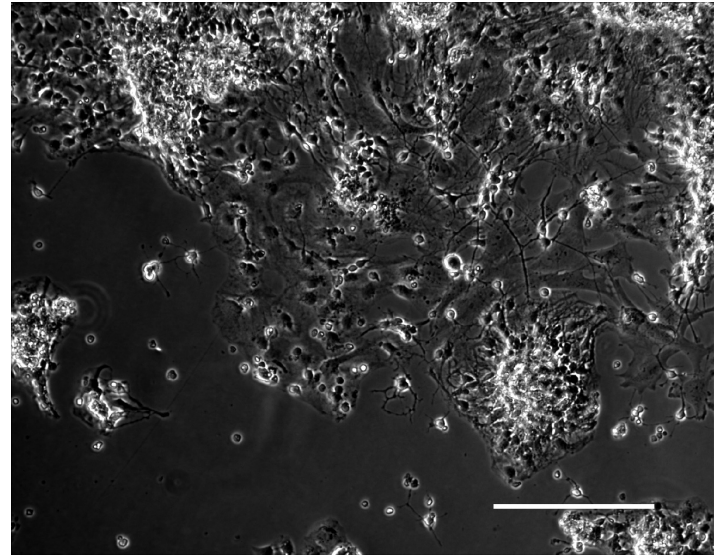

(a)

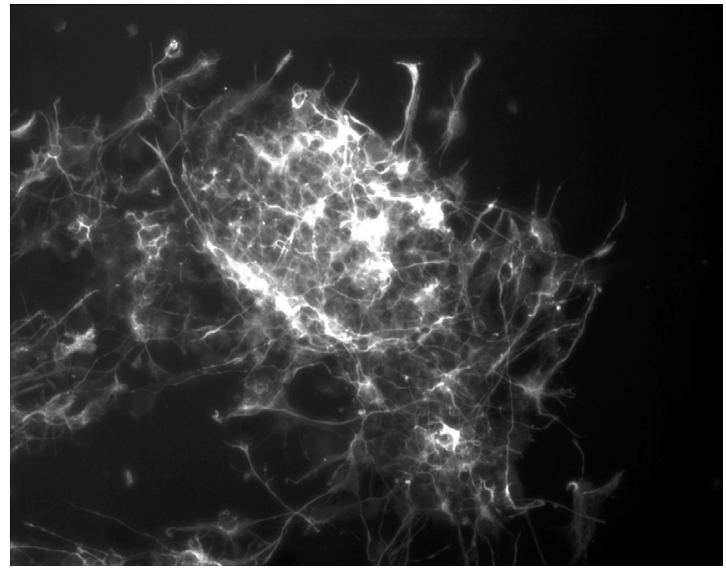

(b)

Fig. 5. (a) Photomicrograph illustrates the morphologic growth of neurospheres cultured on EVAL substrates with or without NGF. (b) These protoplasmic cell layers were characterized as GFAP-immunoreactive astrocytes. Scale bar $=200$ $\mu \mathbf{m}$.

away from their original aggregates and no obvious neurite fasciculation was found under serum conditions, regardless of the presence or absence of NGF. Moreover, under serum conditions, the process length and breadth of differentiated neurospheres cultured on EVAL substrates with or without the addition of NGF have no significant difference (data not shown).

The purpose of the present study is to focus on the effects of cell-biomaterial and cell-cell interactions on the developmental potential of stem cells from embryonic rat cerebral cortex. In order to interpret the phenomenon further, we proposed the mediation of cell-biomaterial interaction by cell-cell interaction should be taken into account. In this study, under 
serum free conditions, although straight and thin differentiated processes were found, the amount or maturity of differentiated neurons were not enough to form neurites fasicles without the addition of NFG. These differentiated processes from neurosphereforming cells shows relatively little tendency to fasciculate. Since the NGF are capable to improve better neuronal growth and neurites elongation, when the NGF was present in the above culture system, more neurons were differentiated from forming-neurosphere cells, as a consequence, neurite fasiculation were observed. The behavior of fasciculation of neurites may be due to the affinitive competitions between neuron-neuron and neuron-substrate. In this case, because the neuron-neuron affinity is stronger than neuron-EVAL affinity, neurites outgrowth was primarily in large fascicles in the presence of NGF. In contrast, when serum proteins were added in the medium, many forming-neurosphere cells were induced to differnetiate into glail cells and is more adherent to EVAL substrates than neurons. At this time, process-bearing cells were grown on astrocyte layers, and neurites did not fasciculate. It may be due to that the neuron-glia interaction is stronger than neuron-neuron interaction resulting in neurites failed to fasciculate. In addition, these glia layers may form a barrier between neurons and EVAL substrates and inhibited the interactions between them. These results confirmed previous studies [10], which suggested that neurons aggregated and neurites fasciculated on nonglial layer but not on glial layer. In this study, EVAL substrates serve as nonglial layer while seruminducing differentiated astrocytes serve as glial layer. The influence of glial and nonglial layers on the morphology of neuronal growth could theoretically be due to either to cell surface interactions or to soluble factors which could cause alternations in neurite adherence to the substrates or to the neurites. Finally, these pattern of neural stem cell growth on EVAL subtrates with or without NGF in the absence or presence of serum in this studies also suggested that there exist hierarchies of adherence in the nervous system such that CNS neurons are more adherent to glail cells than to other neurons but are more adherent to other neurons than to EVAL substrates.

\section{CONCLUSION}

In summary, the present study provide evidence that EVAL can be a potent controller of cell interactions involving cell-cell and cell-substrate contacts. We proposed that, in combination with nerve growth factors, EVAL substrates could induce neurite fasciculation of embryonic rat cortical neural stem cells under serum free conditions These in vitro results are very encouraging since this information should be useful for the development of strategies for regulating the differentiation and fate determination of neural stem cells.

\section{ACKNOWLEDGEMENT}

The authors thank National Taiwan University Hospital and National Science Council of the Republic of China for their financial support of this research.

\section{REFERENCES}

1. Johe KK, Hazel TG, Muller T, Dugich-Djordjevic MM, McKay RD. Single factors direct the differentiation of stem cells from the fetal and adult central nervous system. Genes Dev 1996;10:312940.

2. Tsai RY, McKay RD. Cell contact regulates fate choice by cortical stem cells. J Neurosci 2000;20:3725-35.

3. Cameron HA, Hazel TG, Mckay RDG. Regulation of neurogenesis by growth factors and neurotransmitters. J Neurobiol 1998;36:287-306.

4. Reynolds BA, Weiss S. Generation of neurons and astrocytes from isolated cells of the adult mammalian central nervous system. Science 1992;255:1707-10.

5. Ciccolini F, Svendsen CN. Fibroblast growth factor 2 (FGF-2) promotes acquisition of epidermal growth factor (EGF) responsiveness in mouth striatal precursor cells: Identification of neural precursors responding to both EGF and FGF-2. J Neurosci 1998;18:7869-80.

6. Arsenijevic Y, Weiss S, Schneider B, Aebischer P. Insulin-like growth factor-1 is necessary for neural stem cell proliferation and demonstrates distinct actions of epidermal growth factor and fibroblast growth factor-2. J Neurosci 2001;21:7194-202.

7. Shimazaki T, Shingo T, Weiss S. The ciliary neurotrophic factor/leukemia inhibitory factor/gp 130 receptor complex operates in the maintenance of mammalian forebrain neural stem cells. J Neurosci 2001;21:7642-53.

8. Schmidt CE, Leach JB. Neural tissue engineering: strategies for repair and regeneration. Annu Rev Biomed Eng 1993;5:293-347.

9. Young $\mathrm{TH}$, Hung $\mathrm{CH}$. Behavior of embryonic rat cerebral cortical stem cells on the PVA and EVAL substrates. Biomaterials 2005;26:4291-99.

10. Noble M, Fok-Seang J, Cohen J. Glia are a unique substrate for the in vitro growth of central nervous system neurons. J Neurosci 1984;4(7):1892-903. 
11. Young TH, Yao CH, Sun JS, Lai CP, Chen LW. The effect of morphology variety of EVAL membranes on the behavior of myoblasts in vitro. Biomaterials 1998; 19:717-724.

12. Bottenstein JE, Sato GH. Growth of a rat neuroblastoma cell line in serum-free supplemented medium. Proc Natl Acad Sci USA 1979;76:514-7

13. Wong G, Goldshmit Y, Turnley AM. Interferon- $\gamma$ but not TNF $\alpha$ promotes neuronal differentiation and neurite outgrowth of murine adult neural stem cells. Exp Neurol 2004;187:171-7.

14. Chiang YH, Silani V, Zhou FC. Morphological differentiation of astroglial progenitor cells from EGF-responsive neurospheres in response to fetal calf serum, basic fibroblast growth factor, and retinal. Cell transplant 1996;5(2):179-89.

15. Gritti A, Parati EA, Cova L, Frolichsthal P, Galli R, Wanke E, Faravelli L, Morassutti DJ, Roisen F, Nickel DD, Vescovi AL. Multipotential stem cells from the adult mouse brain proliferate and selfrenew in response to basic fibroblast growth factor. J Neurosci 1996;16:1091-100.

16. Weclewicz K, Svensson L, Billger M, Holmberg K, Wallin M, Kristensson K. Microtubule-Associated Protein 2 Appears in Axons of Cultured Dorsal Root Ganglia and Spinal Cord Neurons After Rotavirus Infection. J Neurosci Res 1993;36:17382.

17. Dráberová E, Lukás Z, Ivanyi D, Viklický V, Dráber P. Expression of class III beta-tubulin in normal and neoplastic human tissue. Histochem Cell Biol 1998;109:231-9.

18. Bignami A, Eng LF, Dahl D, Uyeda CT. Localization of the glial fibrillary acidic protein in astrocytes by immunofluorescence. Brain Res 1972;43:429-35. 